\title{
Inhibition of Mild Steel Corrosion in Sulfuric Acid Solution Using Extraction of Linum Usitatissimum Seeds
}

\author{
Hassan Elgahawi* ${ }^{*}$ \{Mohamed Gobara, Ahmad Baraka, Waleed Elthalabawy $\}^{\dagger}$
}

\begin{abstract}
Inhibitive effect of Linum Usitatissimum (LU) on the acid corrosion of mild steel in $1 \mathrm{M} \mathrm{H}_{2} \mathrm{SO}_{4}$ solution was studied by weight loss, Potentiodynamic polarization and electrochemical impedance spectroscopy (EIS). Linum Usitatissimum effectively inhibited the corrosion of mild steel with efficiency ranges from 85.7 to $95.5 \%$ for LU concentrations from 80 to $1200 \mathrm{ppm}$. EIS showed that the charge transfer governs the corrosion process of mild steel in $1 \mathrm{M} \mathrm{H}_{2} \mathrm{SO}_{4}$ solution. Adsorption isotherm study was performed using weight loss measurements where Langmuir and El-Awady models were applied on data to investigate the model of adsorption. Corrosion inhibition was also tested at different temperatures to measure the thermodynamic parameters; $\Delta G^{\circ}, \Delta H^{\circ}, \Delta S^{\circ}$ and $E_{\mathrm{a}}$. Inhibition was suggested to occur due to adsorption phenomenon and data obey the Langmiur model. Thermodynamic study reveals that adsorption is exothermic-physical process driven by entropic factors. The morphology study using SEM confirms the electrochemical investigation where the corrosion resistance increases with increase of inhibitor concentration.
\end{abstract}

Keywords: Corrosion; Linum Usitatissimum; Mild steel; EIS; SEM.

\section{Introduction}

Acid solutions are widely used in industry such as acid pickling, industrial acid cleaning reaction, acid de-scaling and oil well acidizing.

The precaution is required in the selection of materials to handle acids even in relatively dilute concentrations. Mild steel is often employed in many industrial applications that deal with acids because of its availability, low cost, and uncomplicated fabrication. However, mild steel is susceptible to different forms of corrosion when in contact with acids. Sulfuric acid is one of the most difficult common acids to handle when considering corrosion.

There are various organic inhibitors that decrease the corrosion rate of mild steel in acidic solutions [1]. The efficiency of an organic inhibitor is mainly dependent on its ability to be adsorbed on the metal surface. Organic inhibitors are compounds that usually contain heteroatoms (such as $\mathrm{O}, \mathrm{N}, \mathrm{S}$ ) and multiple bonds in their molecules through which they are adsorbed on the metal surface [1]. These compounds either form strong co- ordination bonds with metal atoms or form passive films on the surface [2] .

The purpose of this study is to investigate the inhibition action of Linum Usitatissimum inhibitor for the corrosion on mild steel in sulfuric acid using Potentiodynamic, polarization and electrochemical impedance spectroscopy (EIS).

\footnotetext{
Libyan Armed Forces, Libya.

$\dagger$ Egyptian Armed Forces, Egypt.
} 


\section{Corrosion Measurements for Mild Steel in $\mathbf{1 M ~ H}_{2} \mathrm{SO}_{4}$}

There are many methods of corrosion behavior investigation; the selected techniques in this study are weight loss, Potentiodynamic polarization and EIS.

\subsection{Potentiodynamic Polarization}

Cathodic and anodic kinetics reactions are great importance for studying corrosion process. When applying inhibitors, the most adaptable technique for investigating corrosion kinetics is potentiodynamic polarization. Figure (1) shows anodic and cathodic polarization of the mild steel in sulfuric acid solutions with and without the addition of different concentrations of LU. The figure shows that as the inhibitor concentration increases, the corrosion current decreases. In addition, the corrosion potentials $\left(E_{\text {corr }}\right)$ does not show a dramatic change be increasing inhibitor concentration. Table 1 gives the electrochemical kinetic parameters of Tafel extrapolations $\left(E_{c o r r}, \beta c, \beta a, I_{\text {corr }}\right.$, and $\left.I E \%\right)$. From the Table, the increase of inhibitor concentration causes a considerable regular decrease in corrosion current density $\left(I_{c o r r}\right)$ which indicates the increase of inhibition efficiency $(I E \%)$. This result suggests that LU acts as adsorption inhibitor [3].

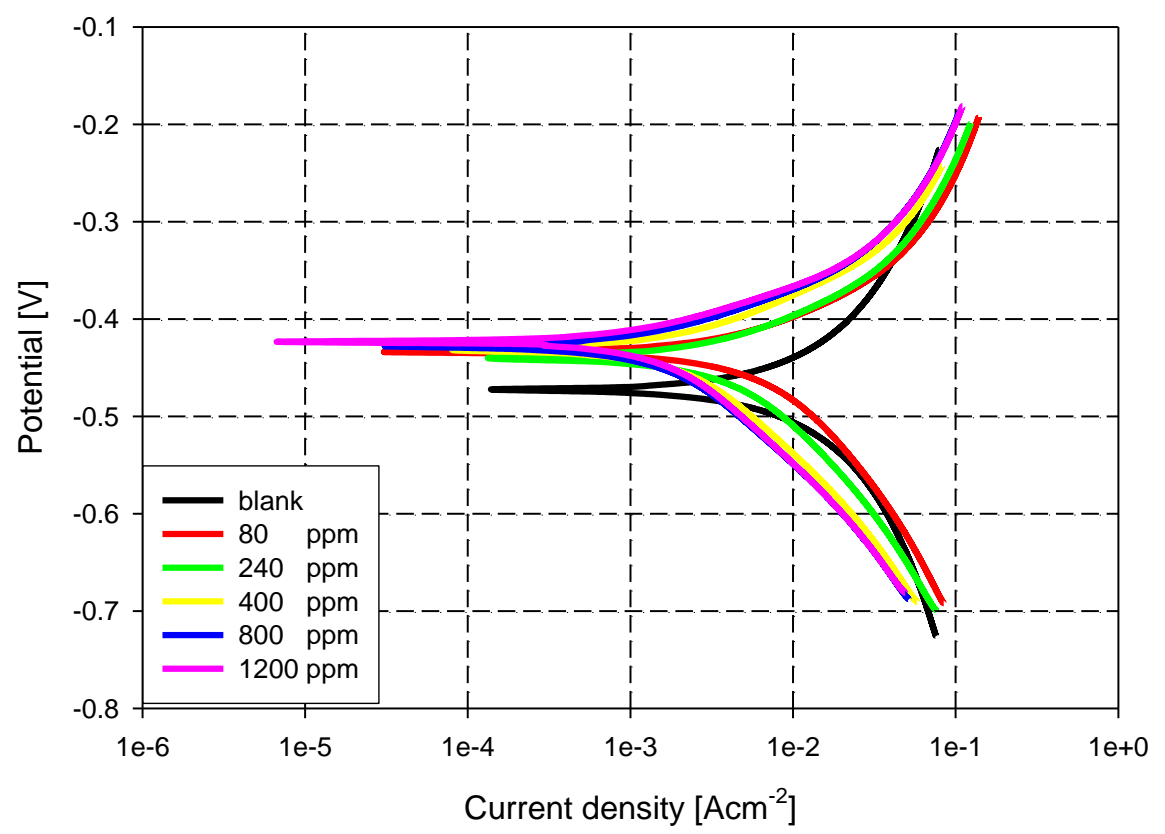

Fig. (1) Tafel plots of mild steel in $1 \mathrm{M} \mathrm{H}_{2} \mathrm{SO}_{4}$ with different concentrations of LU inhibitor at room temperature

Table (1) Corrosion kinetic parameters with different concentrations of LU inhibitor

\begin{tabular}{|c|c|c|c|c|c|}
\hline Conc. $L U[\mathrm{ppm}]$ & $\beta_{\mathrm{a}}[\mathrm{mV} / \mathrm{dec} a d e]$ & $\beta_{\mathrm{c}}[\mathrm{mV} / \mathrm{dec}$ dede $]$ & $E_{\text {corr }}[\mathrm{mV}]$ & $I_{\text {corr }}\left[\mathrm{mA.cm}^{-2}\right]$ & $I E \%$ \\
\hline 0 & 1226.6 & 1465.4 & -473 & 872 & - \\
\hline 80 & 204.0 & 314.8 & -434 & 124 & $85.7 \%$ \\
\hline 240 & 188.2 & 290.7 & -440 & 89.4 & $89.7 \%$ \\
\hline 400 & 163.5 & 249.9 & -436 & 54.1 & $93.7 \%$ \\
\hline 800 & 139.5 & 218.7 & -428 & 31.0 & $96.4 \%$ \\
\hline 1200 & 137.7 & 222.6 & -423 & 30.5 & $96.5 \%$ \\
\hline
\end{tabular}


Figure (2) clarifies the relation between the inhibitor concentration and corrosion current density. Also, it gives the impact of inhibitor concentration on $I E \%$ where the inhibitor percent reaches to $96.5 \%$. Moreover, the slopes of both cathodic and anodic branches $\left(\beta_{c}\right.$ and $\beta_{a}$ respectively) are gradually decreased by increasing the inhibitor concentration. Besides, the corrosion potential $\left(E_{c o r r}\right)$ seems to be stable where it changes within $50 \mathrm{mV}$ (between -473 to $-423 \mathrm{mV}$ ) as given in Table 1.The above results indicate that LU is mixed-type inhibitor where inhibition occurs for both anodic and cathodic reactions by adsorption [4]. Therefore, both metal dissolution reaction and hydrogen ion reduction are inhibited by LU inhibitor.

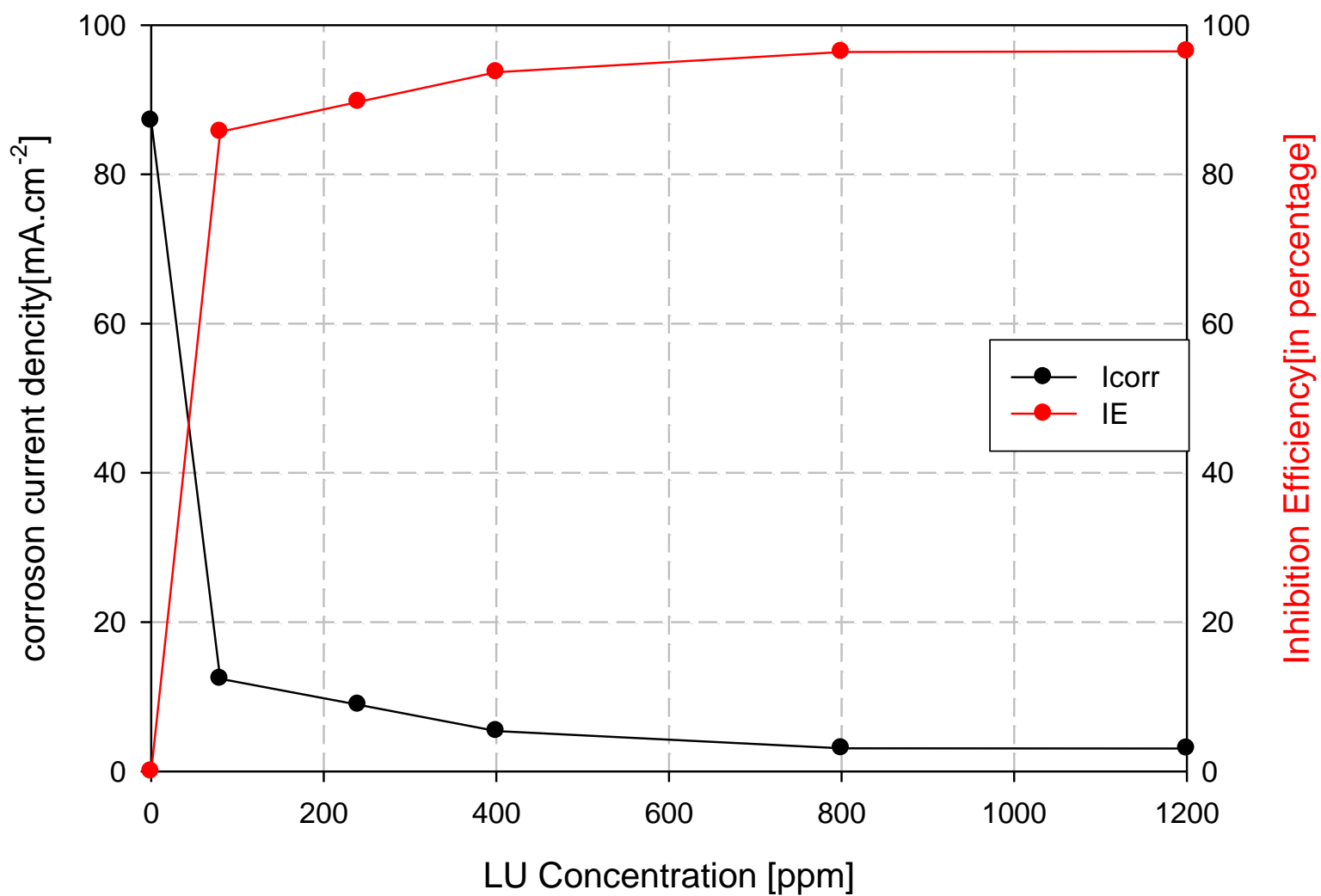

Fig. (2) Relation between inhibitor concentration and corrosion current density and IE\%

\subsection{Electrochemical Impedance Spectroscopy (EIS)}

EIS technique has been used to investigate the interaction between the metal substrate and the acidic solution in the presence and absence of inhibitor [5]. Electrochemical impedance plots; Nyquist and Bode, of mild steel in 1M sulfuric acid with and without LU inhibitor are shown in Figs. (3), (4) and (5) respectively. Figure (3) Nyquist plots, shows one semicircle for each sample with and without adding the LU inhibitor. The shape of the semicircle seems to be identical with the difference in diameter that increases with increasing the inhibitor concentration. This behavior illustrates that adding inhibitor does not adapt the anodic or cathodic electrochemical reactions; it only decreases the rate of both reactions. Furthermore, the single semicircle indicates that a single time constant controls the corrosion process, which is the charge transfer process. The unsymmetrical shape of the semicircle may be due to surface inhomogeneity and/or the dispersion of frequency. The figure also shows an inductive loop accompanying the use of an inhibitor. This inductive loop, in the low-frequency range, may be attributed to relaxation process that occurs during adsorption process [6]. 
The Bodes plots (impedance and phase Figs. (4) and (5) respectively) confirm the Nyquist plot results where the impedance increases as the inhibitor concentration increases. Also, the phase plot shows a single time constant which increases with the increase of inhibitor concentration.

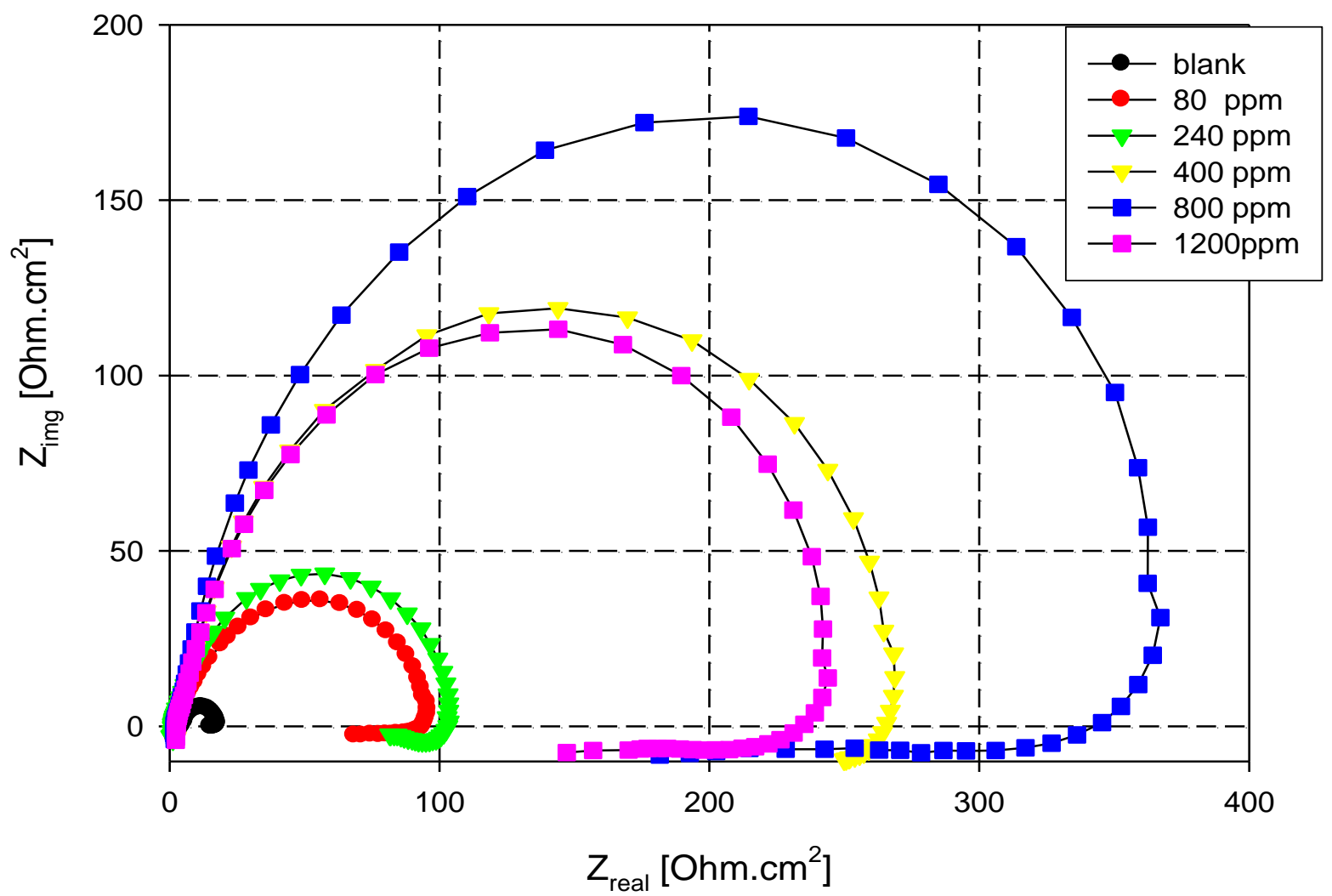

Fig. (3) Nyquist plots of mild steel samples in 1M H2SO4 solution with different concentrations of LU inhibitor at room temperature.

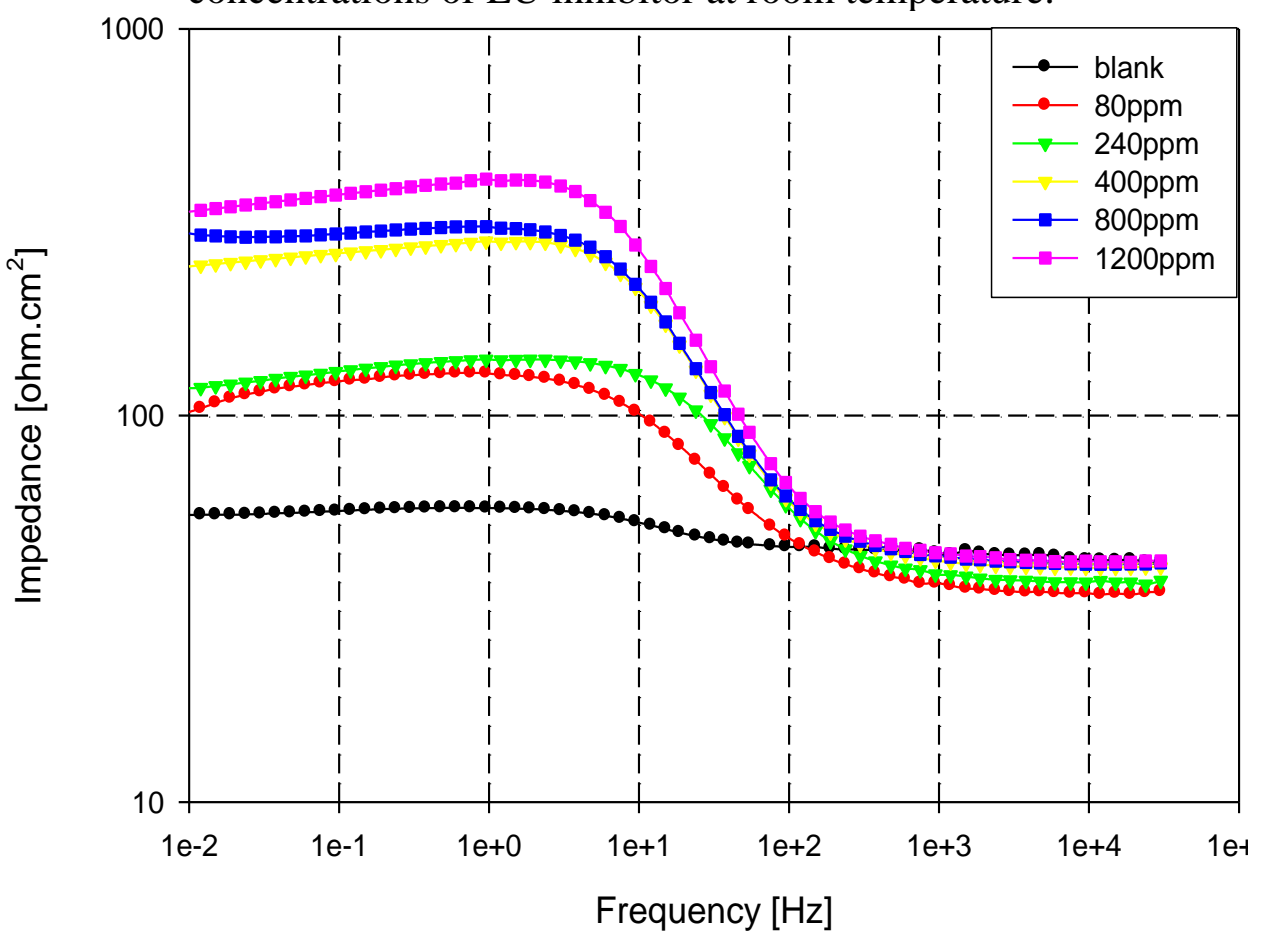

Fig. (4) Impedance plots of mild steel samples in 1M H2SO4 solution with different concentrations of LU inhibitor at room temperature. 


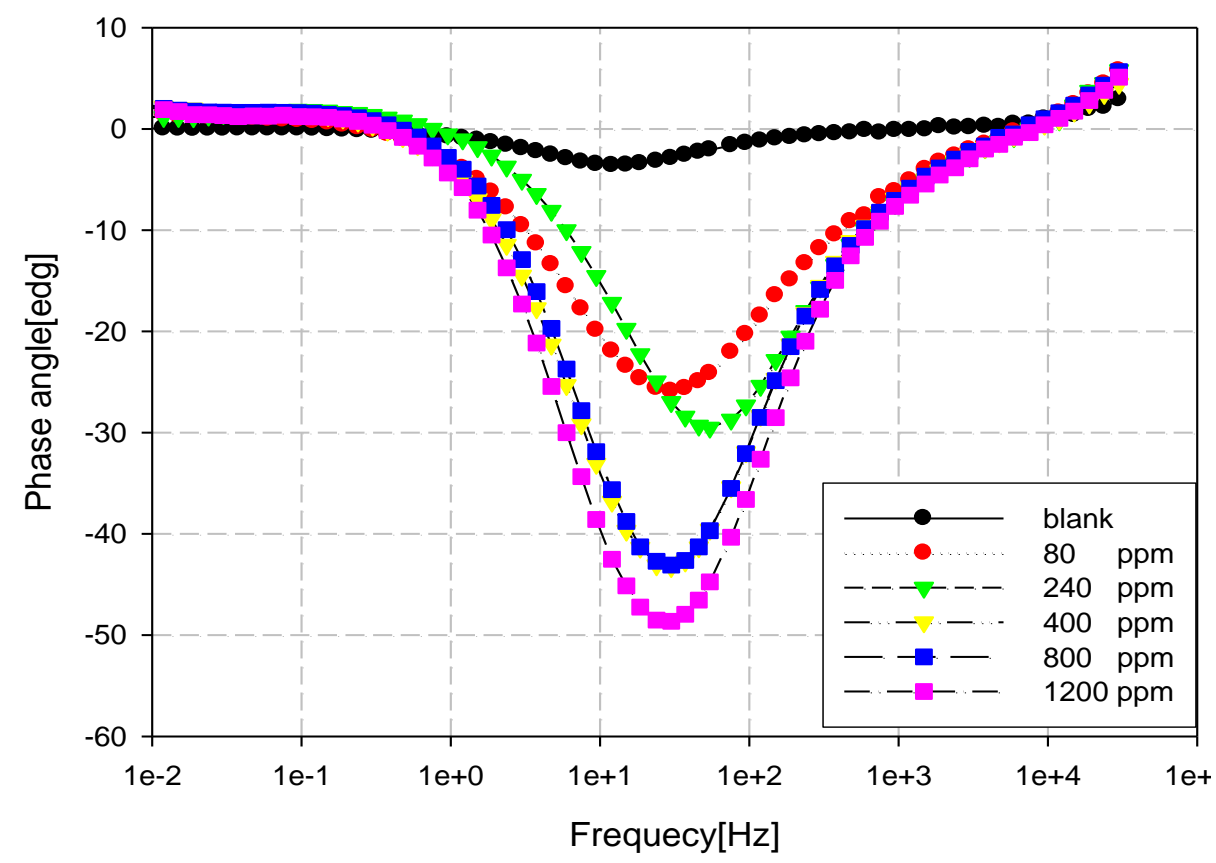

Fig. (5) Phase angel plots of mild steel samples in 1M H2SO4 solution with different concentrations of LU inhibitor at room temperature.

One of the most main important of EIS technique is to obtain qualitative information by fitting EIS data to an equivalent electrical circuit. The electrical equivalent circuits, shown in Fig. (6), were used to model the EIS experimental data where $R_{s}$ represents the ohm solution resistance (between the working and reference electrode); $R_{c t}$ is the charge transfer resistance associated with corrosion process at $O C P ; C_{d l}$ is the electric doublelayer capacitance at metal/electrolyte interface and $L$ is an inductor. Such circuit has been widely used for steel corrosion in sulfuric acid solution [7]. Due to non-ideal frequency response during experimental work, a pure capacitor, $C$, is usually replaced by constant phase element $(C P E)$. The capacitance values, $C$, can be calculated from constant phase element (CPE) and $R_{c t}$ according to the following equation [8].

$$
C_{d l}=\frac{Y_{0} \omega^{n-1}}{\sin (n \pi / 2)}
$$

where $Y \circ$ is the $C P E$ constant, $\omega$ is the angular frequency $(\mathrm{rad} / \mathrm{s})$ and $\mathrm{n}$ is the $C P E$ exponent. The $C P E$ becomes pure capacitor when $\mathrm{n}=1$.
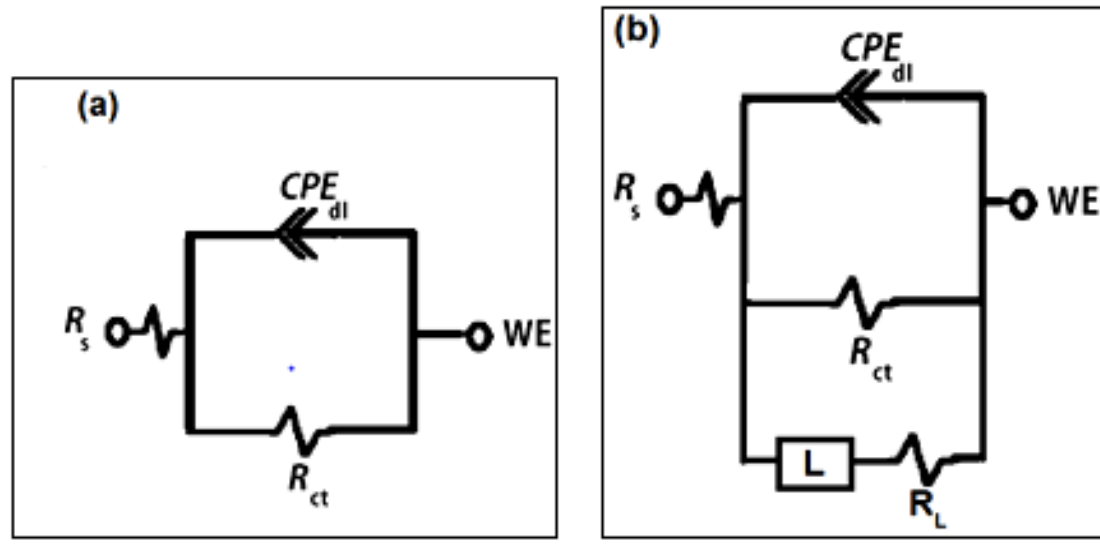

Fig. (6) Equivalent electrical circuits used for numerical fitting of the EIS data (a) in absent of LU inhibitor (b) in presence of LU inhibitor. 
The change of both charge transfer resistance and double layer capacitance of mild steel in $1 \mathrm{M} \mathrm{H}_{2} \mathrm{SO}_{4}$ corrosive solution with a different concentration of $\mathrm{LU}$ inhibitor are shown in Fig. (7). It is clear from the figure that the $R_{c t}$ values gradually increase, and $C_{d l}$ suddenly decreases and seems to be stable with the increase of LU concentration indicating a decrease in corrosion rates [9].

These results indicate that the charge transfer governs the corrosion process of mild steel in $1 \mathrm{M} \mathrm{H}_{2} \mathrm{SO}_{4}$ solution. Also, the increase of charge transfer resistance with inhibitor concentration may due to increase of thickness of adsorbed inhibitor. The above results suggest that the adsorption process is physisorption process.

All the EIS fitting parameters with LU concentrations are also summarized in Table 2 These results collectively propose that, there was a significant positive correlation between potentiodynamic polarization and EIS results.

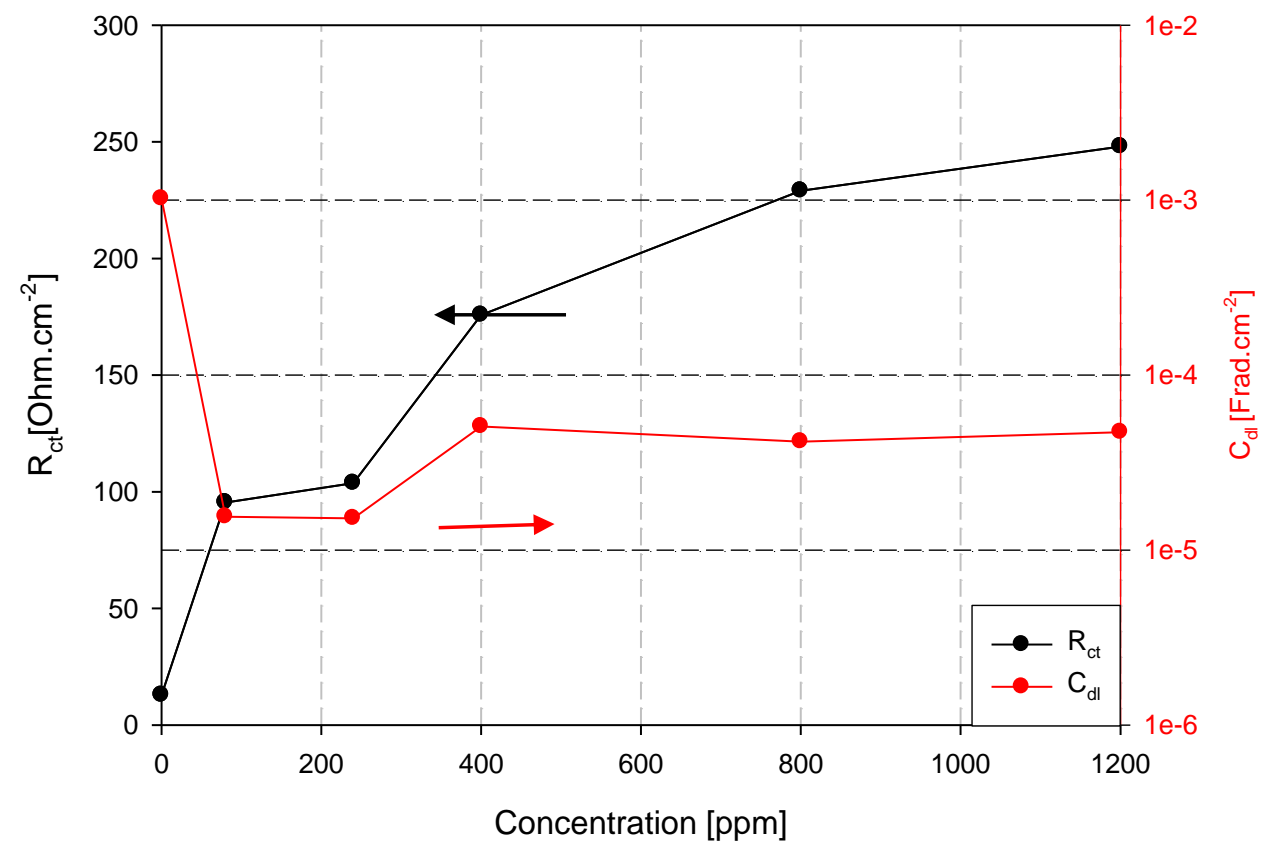

Fig. (7) Equivalent electrical circuits used for numerical fitting of the EIS data (a) in absent of LU inhibitor (b) in presence of LU inhibitor.

Table (2) EIS fitting parameters with Linum Usitatissimum concentrations

\begin{tabular}{|c|c|c|c|c|c|c|}
\hline $\begin{array}{c}\text { Conc. } \\
{[\mathrm{ppm}]}\end{array}$ & $R_{\mathrm{s}}\left[\Omega . \mathrm{cm}^{2}\right]$ & $R_{\mathrm{ct}}\left[\Omega . \mathrm{cm}^{2}\right]$ & $\begin{array}{c}Y_{\mathrm{o}} \\
{\left[10^{-4} \times \text { Frad.cm }\right.}\end{array}$ & $n$ & $\begin{array}{c}\left.C_{\mathrm{dl}}\right] \\
{\left[10^{-5} \times \text { Frad.cm }{ }^{-2}\right]}\end{array}$ & $I E \%$ \\
\hline 0 & 7.80 & 12.8 & 20.80 & 0.91 & 102 & - \\
\hline 80 & 3.40 & 95.4 & 2.80 & 0.92 & 1.05 & $85.7 \%$ \\
\hline 240 & 3.70 & 103.7 & 1.07 & 0.87 & 1.52 & $89.7 \%$ \\
\hline 400 & 4.10 & 175.7 & 0.82 & 0.91 & 5.09 & $93.7 \%$ \\
\hline 800 & 4.20 & 229.1 & 0.65 & 0.92 & 4.16 & $96.4 .0 \%$ \\
\hline 1200 & 4.10 & 248.0 & 0.92 & 0.89 & 4.72 & $96.5 \%$ \\
\hline
\end{tabular}

\section{Adsorption Isotherm and Thermodynamic Parameters}

EIS and potentiodynamic results proposed that adsorption of LU onto mild steel surface plays the main role to inhibit corrosion. Determine the adsorption isotherms are usually used to investigate the adsorption process in several of corrosive solutions. Adsorption isotherm gives an important sight considering the nature of the metal/inhibitor interaction. 
The most applied adsorption isotherm models are Langmuir, Temkin, Freundlich, Frumkin, Flory-Huggins, and El-Awady [7]. Adsorption isotherm models correlate the degree of surface coverage $(\theta)$ with a concentration of the inhibitor at different temperatures. In this study, Langmuir and El-Awady isotherm models were applied. The first model hypostasizes the monolayer coverage of inhibitor over the metal surface [10] while the second hypostasizes the multilayer coverage [11]. The mathematical forms of Langmuir and El-Awady models are as follows respectively:

$$
\begin{gathered}
\frac{C_{\mathrm{inh}}}{\theta}=\frac{1}{K_{\mathrm{ads}}}+C_{\mathrm{inh}} \\
\log \left(\frac{\theta}{1-\theta}\right)=\log K+y \log C_{\mathrm{inh}} \\
\mathrm{K}_{\mathrm{ads}}=\mathrm{K}^{1 / \mathrm{y}}
\end{gathered}
$$

where $C_{\mathrm{inh}}$ is the inhibitor concentration, $\theta$ is surface coverage fraction, $K_{a d s}$ is the equilibrium constant of the adsorption process, and y represents the number of inhibitor molecules that occupies an active site on the surface of the metal substrate. The values of y should be greater than 1 to fit the data with El-Awady model (multilayer model) [11]. The surface coverage, $\theta$, of LU inhibitor on metal surface was calculated from the weight loss data using the following equation [12];

$$
\theta=\frac{w_{\mathrm{o}}-w}{w_{\mathrm{o}}}
$$

where, $w_{0}$ and $w$ are samples weight losses before and after immersion for $72 \mathrm{hr}$ in corrosive solution respectively.

The fitting plots of Langmuir and El-Awady isotherms are shown in Figs. (8) and (9) respectively. The extracted parameters of both models (regression coefficient, $R^{2}$ ) are tabulated in Table 3. From the table, referring to $R^{2}$ values, Langmuir model shows general better fit to experimental data than, El-Awady model. Values of y for all temperatures are less than 1. These gives a preponderance of Langmuir model and therefore single-layer physical coverage of LU on mild steel samples can be suggested.

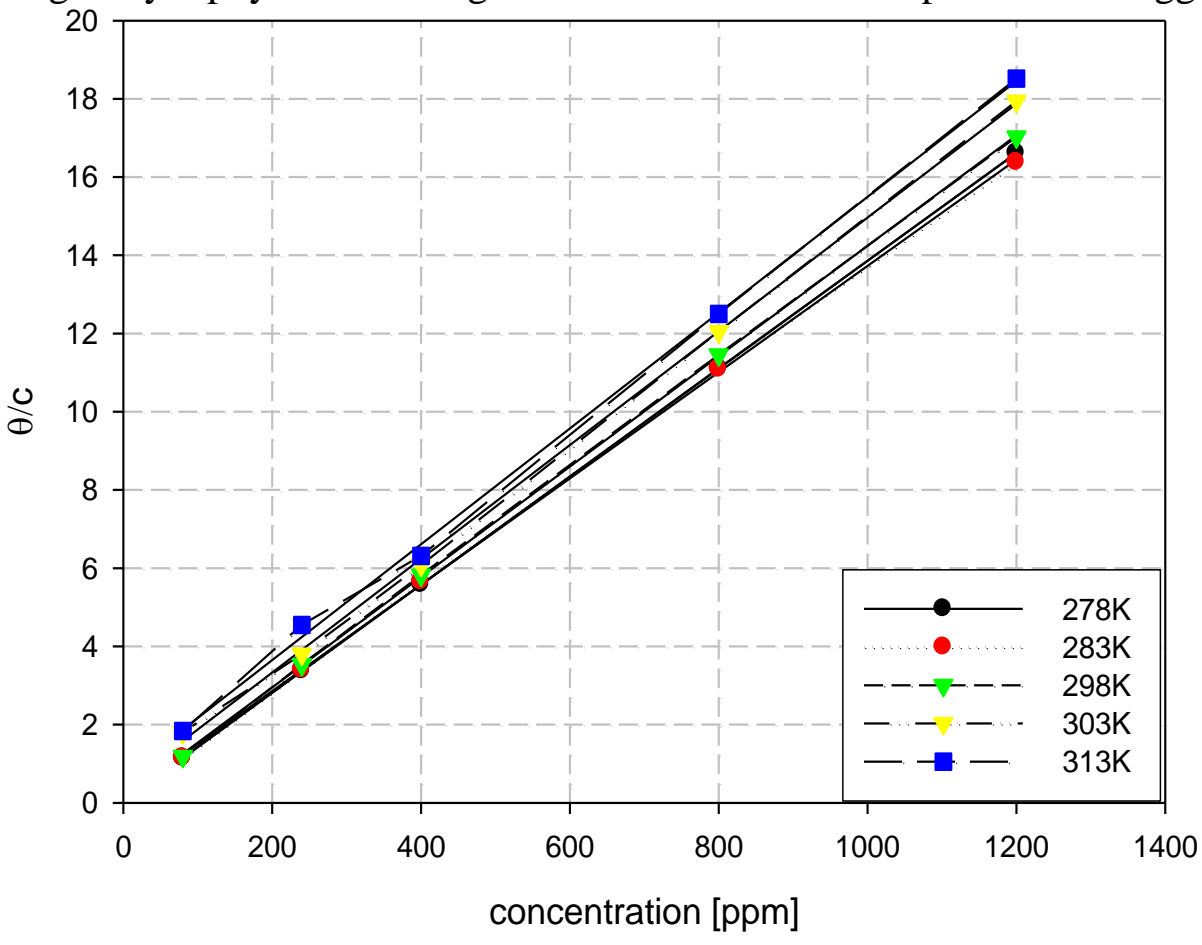

Fig. (8) Langmuir adsorption isotherm for LU on mild steel. 


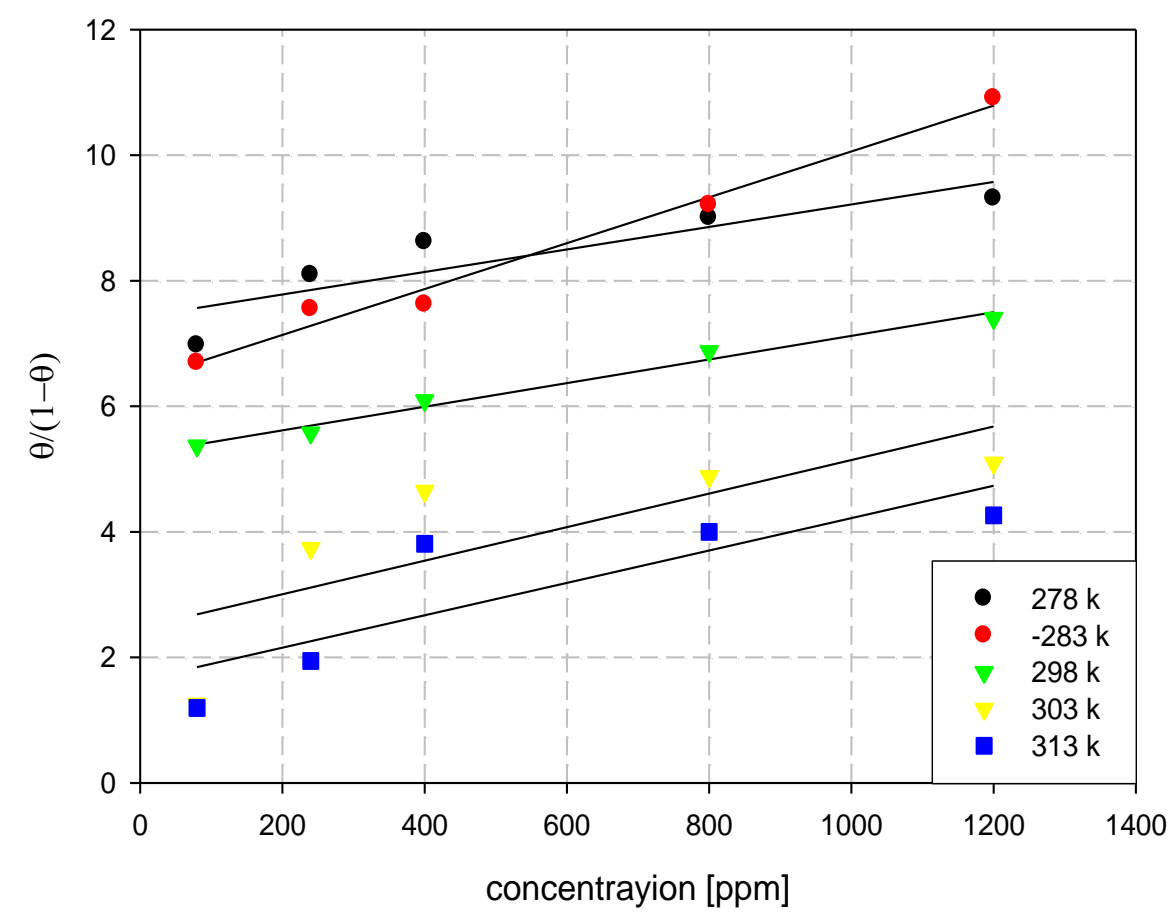

Fig. (9) El-Awady adsorption isotherm for LU on mild steel.

Table (3) Parameters of Langmuir and El-Awady adsorption isotherms

\begin{tabular}{|c|c|c|c|c|c|}
\hline$T[\mathrm{~K}]$ & \multicolumn{2}{|c|}{ Langmuir } & \multicolumn{3}{c|}{ El-Awady } \\
\hline & $K_{\text {ads }}$ & $R^{2}$ & $K_{\text {ads }}$ & $Y$ & $R^{2}$ \\
\hline 278 & 19.4931 & 1 & 1.5 & 0.506 & 0.9057 \\
\hline 283 & 7.0521 & 0.998 & $5.7 \times 10^{4}$ & 0.169 & 0.8773 \\
\hline 298 & 7.993 & 0.999 & $6.8^{\times} 10^{5}$ & 0.122 & 0.9113 \\
\hline 303 & 2.3837 & 0.995 & 2.6 & 0.501 & 0.816 \\
\hline 313 & 1.4273 & 0.999 & $1.3 \times 10^{8}$ & 0.1045 & 0.9758 \\
\hline
\end{tabular}

The adsorption spontaneity of organic inhibitors on metal surface identifies the effectiveness of inhibition. Spontaneity can be considered through determining of the apparent free energy of adsorption $\left(\Delta G_{a d s}^{\circ}\right)$. Nature of adsorption, physical or chemical, is also important to indicate the stability of inhibitor on the metal surface. Enthalpy of adsorption process $\left(\Delta H^{\circ}{ }_{a d s}\right)$ can indicate nature of adsorption. Free energy change of adsorption, $\Delta G_{a d s}$, can be calculated from the adsorption constant, $K_{\text {ads }}$, values of ElAwady model from the following equation $[13,14]$. The molecular weight of the inhibitor was calculated from the GC-MS analysis. The inhibitor was find to be a group of fatty acids (will discuss in the next section) and the average molecular weight was used in this study.

$$
\Delta G_{\text {ads }}^{\circ}=-R T \ln \left(55.5 K_{\text {ads }}\right)
$$

where $T$ is the temperature in Kelvin and $R$ is the universal gas constant. Enthalpy change of adsorption, $\Delta H^{\circ}$ ads, and also entropy change, $\Delta S_{a d s}^{\circ}$, of adsorption can be determined by plotting the determined $\Delta G_{a d s}$ versus temperature according to the following thermodynamic relation [15]:

$$
\Delta G_{\text {ads }}^{o}=\Delta H^{o}{ }_{\text {ads }}-T \Delta S^{o} \text { ads }
$$

The plot of $\Delta G^{\circ}$ ads vs. $T$ from which $\Delta H^{\circ}$ ads and $\Delta \mathrm{S}^{\circ}$ ads values (intercept and slope respectively) were determined is shown in Fig. (3). The thermodynamic parameters are 
summarized in Table 3.4. From the table, for all applied temperatures, $\Delta G_{\text {ads }}^{\circ}$ are negative values and negativity gradually decreases with increasing temperature. This indicates that adsorption is spontaneous, and spontaneity is favored as temperature decreases. Also, for the studied temperature range, the absolute values of $\Delta G_{\text {ads }}^{\circ}<40 \mathrm{~kJ} / \mathrm{mol}$ suggesting physical adsorption process [16]. The value of $\Delta H_{a d s}$ is negative indicating an exothermic process which is consistent with physical adsorption. The decrease of $K_{a d s}$ with temperature also confirms the exothermic nature of adsorption process of the inhibitor of the surface of the mild steel. Entropy change, $\Delta S^{\circ}$ ads, is negative indicating a decrease in randomness during adsorption process [17] .It can be concluded that LU adsorption onto mild steel surface is an enthalpy-derived process.

These results suggest that the adsorption of LU inhibitor on mild steel surface in $1 \mathrm{M}$ $\mathrm{H}_{2} \mathrm{SO}_{4}$ aqueous solution is spontaneous physisorption process, and the coverage is single layer type according to Langmuir model $[18,19]$.

Table (4) Thermodynamic parameters

\begin{tabular}{|c|c|c|c|c|}
\hline $\mathrm{T}(\mathrm{K})$ & $K_{a d s}$ & $\Delta G^{\circ}(\mathrm{kj} / \mathrm{mol})$ & $\Delta H^{\circ}(\mathrm{kj} / \mathrm{mol})$ & $\Delta S^{\circ}(\mathrm{J} / \mathrm{mol} . \mathrm{k})$ \\
\hline 278 & 19.4931 & -16.1424 & \multirow{5}{*}{-47.644} & \multirow{5}{*}{-115} \\
\hline 283 & 7.0521 & -14.0458 & & \\
\hline 298 & 7.993 & -14.7739 & & \\
\hline 303 & 2.3837 & -12.3053 & & \\
\hline 313 & 1.4273 & -11.377 & & \\
\hline
\end{tabular}

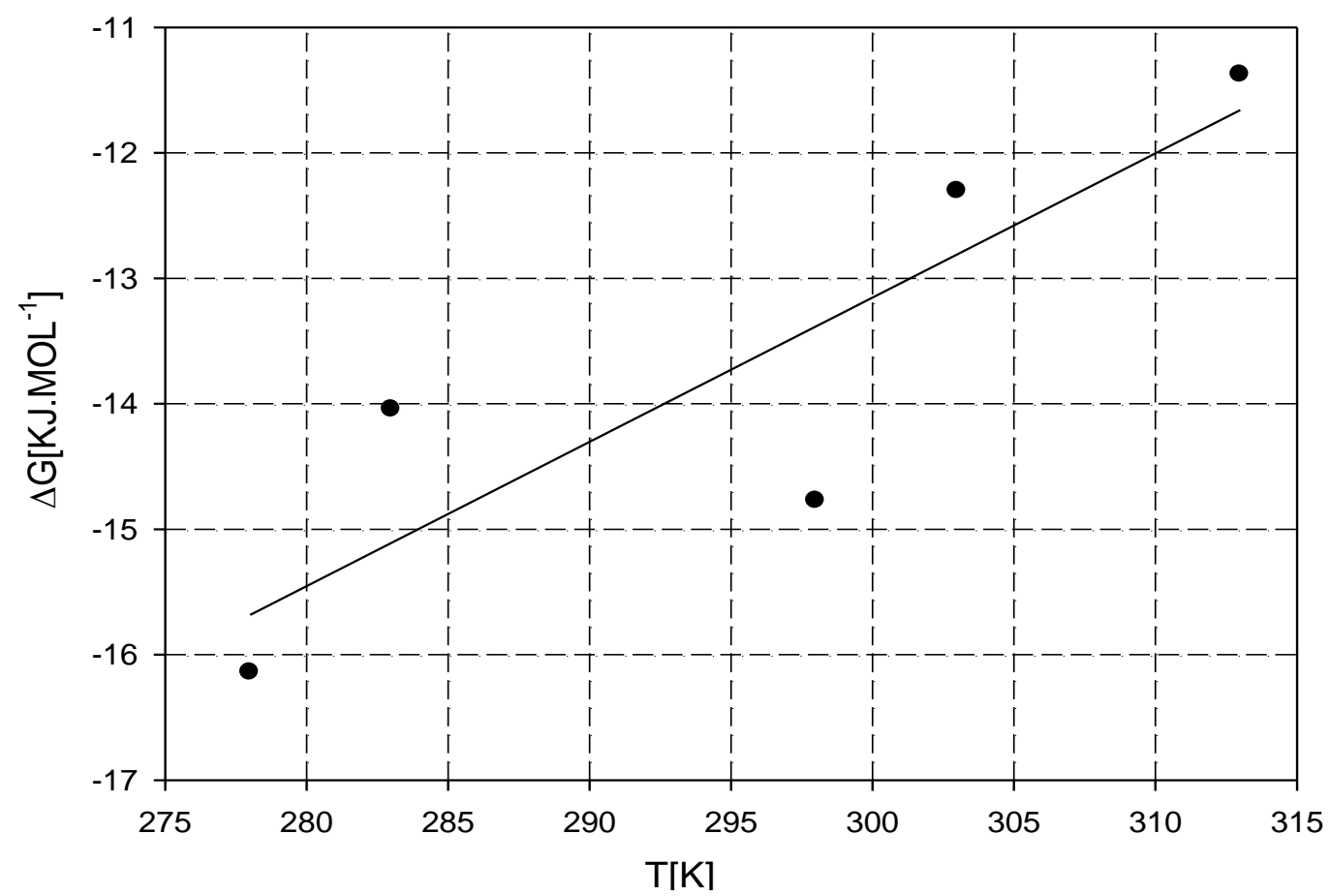

Fig. (10) Change of free energy of adsorption, $\Delta \mathrm{Gads}$, with the temperature.

Activation energy is an important thermodynamic parameter that gives an indication of how difficult the corrosion process takes place. The apparent activation energy $\left(E_{a}\right)$ can be determined from the following modified Arrhenius equation as [20, 21]: 


$$
\ln (C R)=\frac{-E_{\mathrm{a}}}{R T}+\ln A
$$

where $C R$ is the rate of corrosion $\left(\mathrm{mg} \mathrm{cm}^{-2} \mathrm{~h}^{-1}\right), E_{a}$ is the apparent activation energy ( $\mathrm{kJ}$ $\left.\mathrm{mol}^{-1}\right), R$ is the universal gas constant, $A$ is the Arrhenius pre-exponential factor, and $T$ is the absolute temperature. The plot of the corrosion rate, $C R$, of mild steel vs.1/T for different concentrations of inhibitor in $1 \mathrm{M} \mathrm{H}_{2} \mathrm{SO}_{4}$ is shown in Fig. (11). From the figure, corrosion rate increases with temperature increase which is related to exothermic nature of adsorption process of the inhibitor on the mild steel surface.

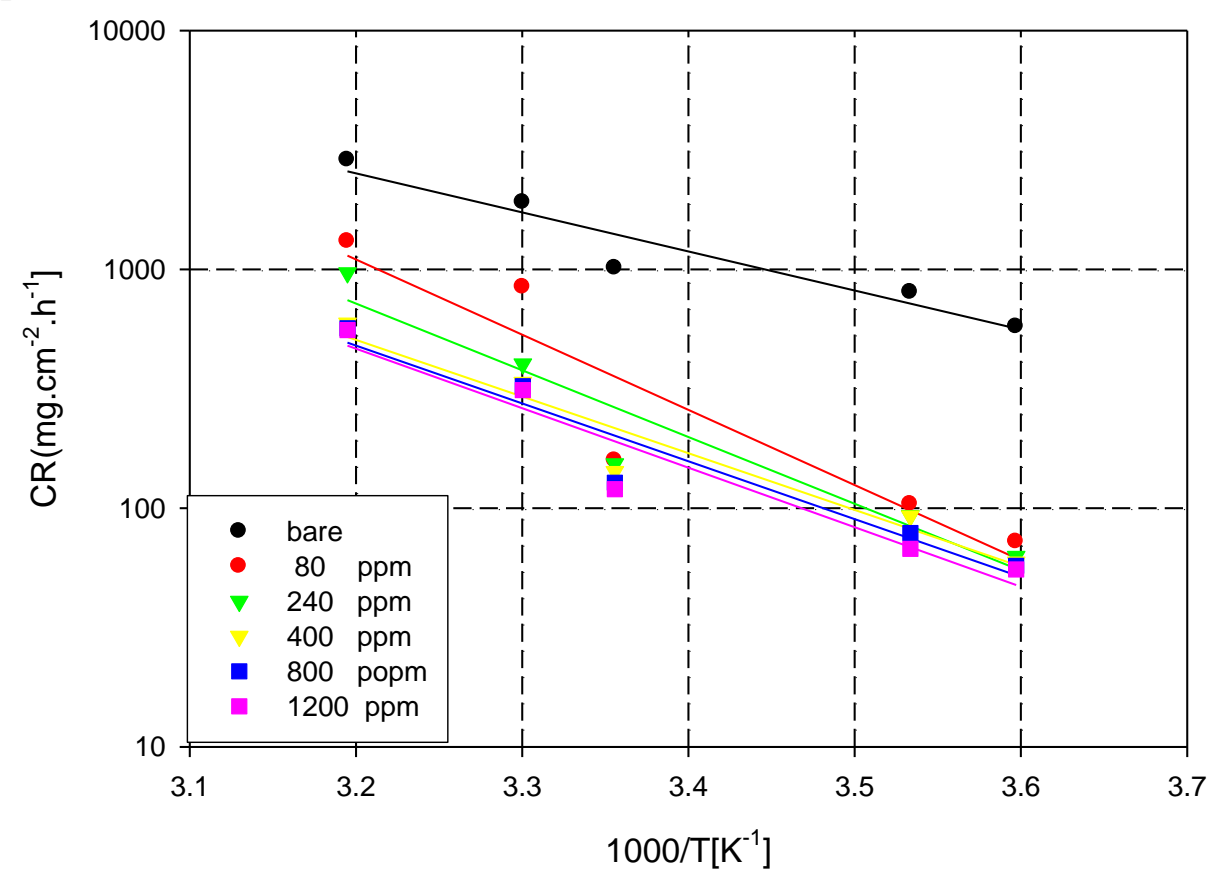

Fig. (11) Change of corrosion rate of mild steel at different LU concentration with the temperature.

The values of $E_{\mathrm{a}}$ can be determined from the slope of the obtained straight lines of the previous relation and presented in Table 5. The table shows that the apparent activation energy increases with increase the inhibitor concentration which means stronger barrier against corrosion action. These results confirm the results of EIS and potentiodynamic polarization.

Table (5) Activation energies for different concentrations of LU

\begin{tabular}{|c|r|}
\hline LU concentration $[\mathrm{ppm}]$ & $E_{\mathrm{a}}[\mathrm{kJ} / \mathrm{mol}]$ \\
\hline Absent & 31.11 \\
\hline 80 & 41.14 \\
\hline 240 & 45.47 \\
\hline 400 & 46.37 \\
\hline 800 & 47.73 \\
\hline 1200 & 53.49 \\
\hline
\end{tabular}

\section{Inhibitor Characterization}

The LU powder content was investigated using GC-MS, the retention time chromatogram is shown in Fig. (12). The noticed intense peaks are recorded at retention times 7.7, 8.9, 9.2, 9.5, 10.5, 10.7 and 12.4 minutes which corresponds to Cetylic acid (4.3\%) palmitic acid (7.8\%), Methyl linolenate (3.1\%), linoleic acid (3.5\%), linolenic acid (14.3\%), Oleic acid amid $(8.1 \%)$ and stearic acid $(56.1 \%)$ respectively. All of these contents represent 
$97.1 \%$ of the extract. The mass spectra of the compounds (not shown) reveal the chemical structure of them and these components are considered as a fatty acid. Table (6) shows the chemical structure, retention time and the percent of each of these components.

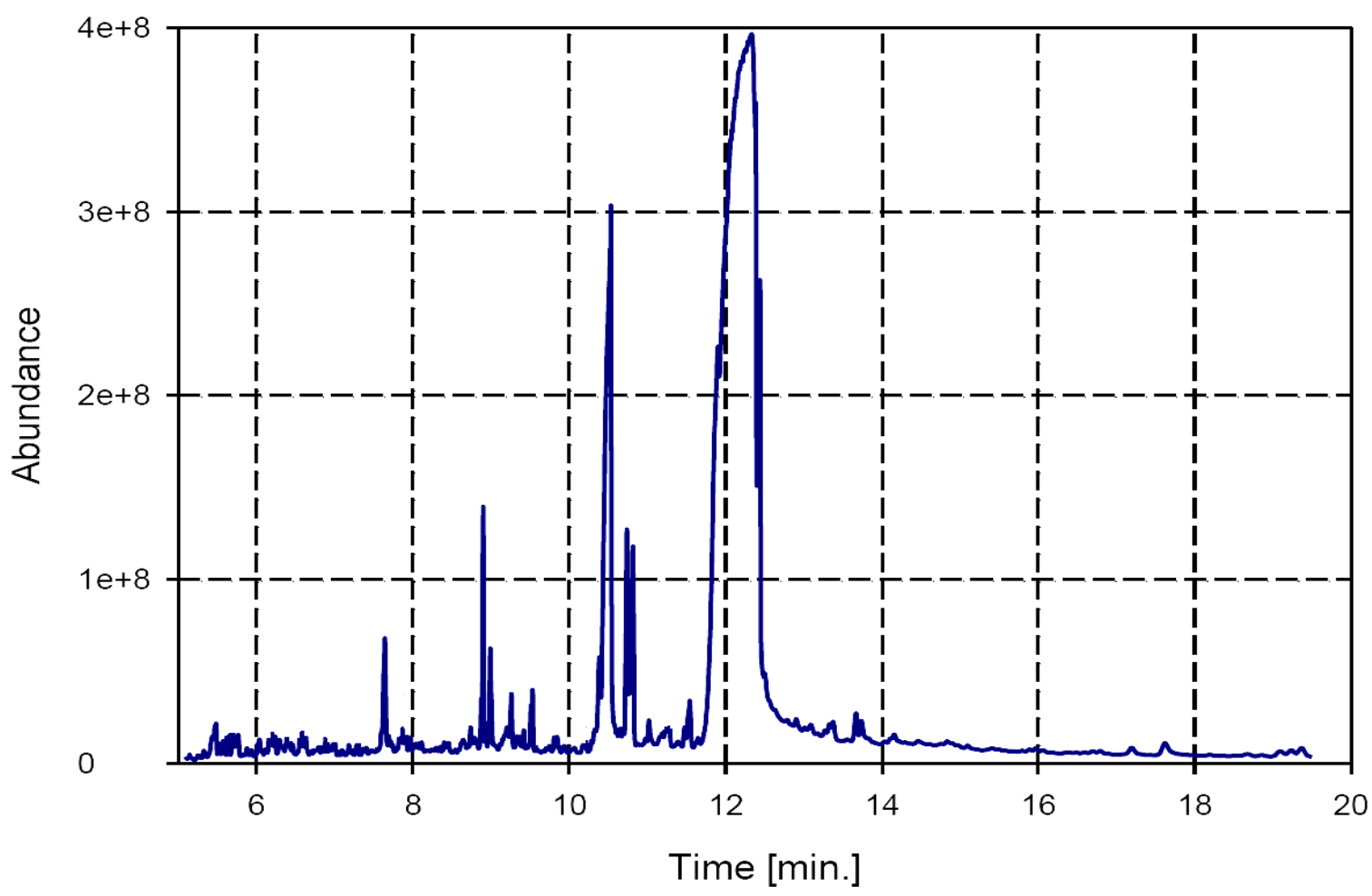

Fig. (12) LU chromatogram

Table (6) Molecular structures of LU Compounds

\begin{tabular}{|l|c|c|c|}
\hline \multicolumn{1}{|c|}{ Compound } & Molecular formula & Retention time [min] & Content \% \\
\hline Cetylic acid & $\mathrm{C}_{18} \mathrm{H}_{30} \mathrm{O}_{2}$ & 7.7 & 4.3 \\
\hline Palmitic acid & $\mathrm{C}_{16} \mathrm{H}_{32} \mathrm{O}_{2}$ & 8.9 & 7.8 \\
\hline Methyl linolenate & $\mathrm{C}_{19} \mathrm{H}_{32} \mathrm{O}_{2}$ & 9.2 & 3.1 \\
\hline Linoleic acid & $\mathrm{C}_{18} \mathrm{H}_{32} \mathrm{O}_{2}$ & 9.5 & 3.5 \\
\hline Linolenic acid & $\mathrm{C}_{18} \mathrm{H}_{30} \mathrm{O}_{2}$ & 10.5 & 14.3 \\
\hline Oleic acid amid & $\mathrm{C}_{18} \mathrm{H}_{35} \mathrm{ON}$ & 10.7 & 8.1 \\
\hline Stearic acid & $\mathrm{C}_{18} \mathrm{H}_{36} \mathrm{O}_{2}$ & 12.4 & 56.1 \\
\hline
\end{tabular}

\section{Fourier Transformation Infra-Red (FTIR) Analysis}

FTIR technique has been used to confirm the adsorption of the organic inhibitor on different metal surfaces [16, 22]. The FTIR spectra of LU and the layer formed on the metal surface after $72 \mathrm{hr}$ immersion in a corrosive solution containing $1200 \mathrm{ppm}$ of LU are shown in Figs. 13-a and 13-b respectively. The broad peak at $3429.8 \mathrm{~cm}^{-1}$ can be assigned to the stretching of an $\mathrm{O}-\mathrm{H}$ group where $\mathrm{CH}_{2}$ and $\mathrm{CH}_{3}$ groups stretching at 2855 and $2930 \mathrm{~cm}^{-1}$ [23]. The peak at $1631.8 \mathrm{~cm}^{-1}$ may be attributed to the stretching mode of $\mathrm{C}=\mathrm{O}$ group and peak at $1388 \mathrm{~cm}^{-1}$ represents the deformation of $\mathrm{CH}_{2}$ and/or $\mathrm{CH}_{3}$ groups. In addition the peak at 1351.1 represents the $\mathrm{C}-\mathrm{H}$ bending. Also a peak appears at 1117.5 which corresponding to $\mathrm{C}-\mathrm{O}$ stretch. The peak at 1597.5 attributed to $\mathrm{N}-\mathrm{H}$ of the amid 
group also the peak at 2954.6 is related to the amid group. By comparison of both spectra, it can be observed that the peaks of the inhibitor molecules are present in the adsorption layer on the mild steel surface. The peak position of some functional groups of the adsorbed inhibitor on the metal surface is slightly shifted than that of neat inhibitor powder; peak at 1117.5 shifted to 1119.4 and peak at 1388 shifted to $1389.6 \mathrm{~cm}^{-1}$. These shifts in wavenumber can be explained by the physisorption process of the inhibitor on the mild steel surface $[24,25]$ which confirms the thermodynamics calculations.
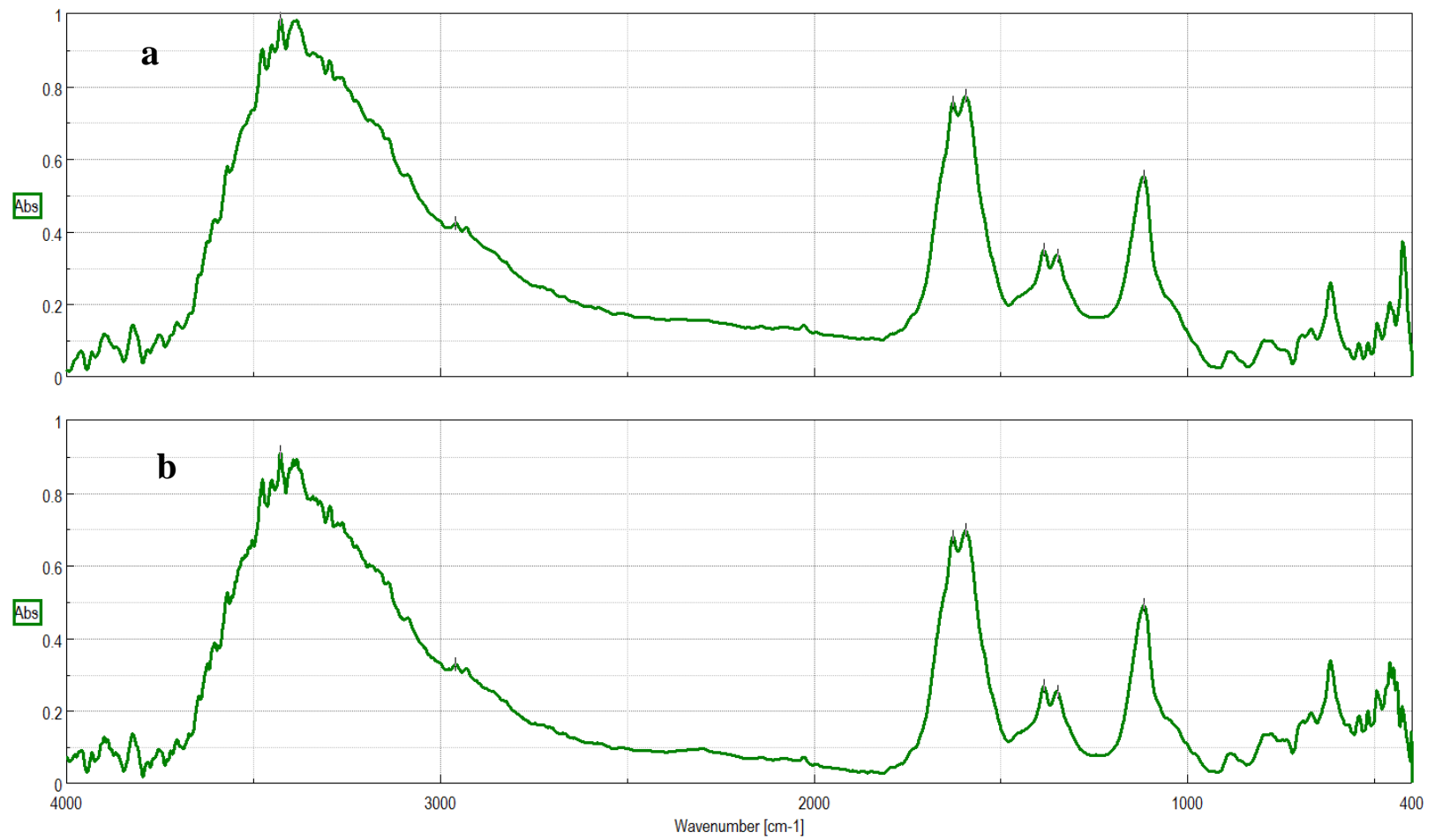

Fig. (13) FTIR spectra of (a) LU (b) adsorption layer formed on the mild steel surface after immersion in 1M H2SO4+1200ppm LU for $72 \mathrm{hr}$.

In General, during immersion of mild steel in solution of sulfuric acid, the sulphate ions are adsorbed on the positively charged metal substrate [2]. The positive charge on the metal substrate motivates the adsorption of $\mathrm{SO}_{4}{ }^{2-}$ ions and the metal surface becomes negatively charged as follows;

$$
\begin{aligned}
& \mathrm{Fe}^{2+}+\mathrm{SO}_{4}{ }^{2-} \rightarrow\left[\mathrm{Fe}\left(\mathrm{SO}_{4}{ }^{2-}\right)\right] \text { ads } \\
& {\left[\mathrm{Fe}\left(\mathrm{SO}_{4}{ }^{2-}\right)\right] \text { ads } \rightarrow[\mathrm{FeSO} 4] \text { ads }+2 \mathrm{e}^{-}} \\
& {\left[\mathrm{FeSO}_{4}\right]_{\mathrm{ads}} \rightarrow \mathrm{Fe}^{2+}+\mathrm{SO}_{4}{ }^{2-}}
\end{aligned}
$$

Fatty acids are suggested to be protonated in sulfuric acid from FTIR result [26]. Consequently, the protonated fatty acids could attract to sulphate anion layer that physically adsorbed on the metal surface prohibiting further adsorption of sulphate anion i.e. no sulphate anions can reach metal surface. Also, the presence of non-bonded electron pairs of oxygen and nitrogen atoms, persuade the adsorption of the LU inhibitor molecules on the metal surface and may react with Fe ions forming complexes which could be adsorbed on a metal surface hindering the interaction of iron ions with the acidic solution [27]. Finally, the large size and molecular weight of the constituents of the extract of Linum Usitatissimum play a major role in hindering the corrosion process by covering a wide area of the metal surface [12].

\section{SEM Analysis}

Figure (14) shows the SEM images of the samples after immersion in $1 \mathrm{M} \mathrm{H}_{2} \mathrm{SO}_{4}$ for 72 hr. Figure (14-a) showed the surface characteristics of the mild steel sample immersion in 
$1 \mathrm{M} \mathrm{H}_{2} \mathrm{SO}_{4}$ in absence of inhibitor. Figures (14 b, c, d, e and f) show the SEM images of samples with increase of inhibitor concentration from 80, 240, 400, 800 and $1200 \mathrm{ppm}$ of inhibitor respectively. The images clarify that as the inhibitor concentration increase the corrosion products and pits number decrease. For high inhibitor concentration (1200 ppm) the image of SEM displayed, that it was hardly to notice any corrosion products and pits on the surface of mild steel. In other hand, the image of blank (absence of inhibitor) sample shows sever corrosion and the corrosion products significantly covert the whole sample surface with some pits.

The obtained results are in covenant with the electrochemical analysis. So, on the basis of the results, it could be stated that LU inhibitor remarkably inhibited corrosion process of mild steel in $1 \mathrm{M} \mathrm{H}_{2} \mathrm{SO}_{4}$.
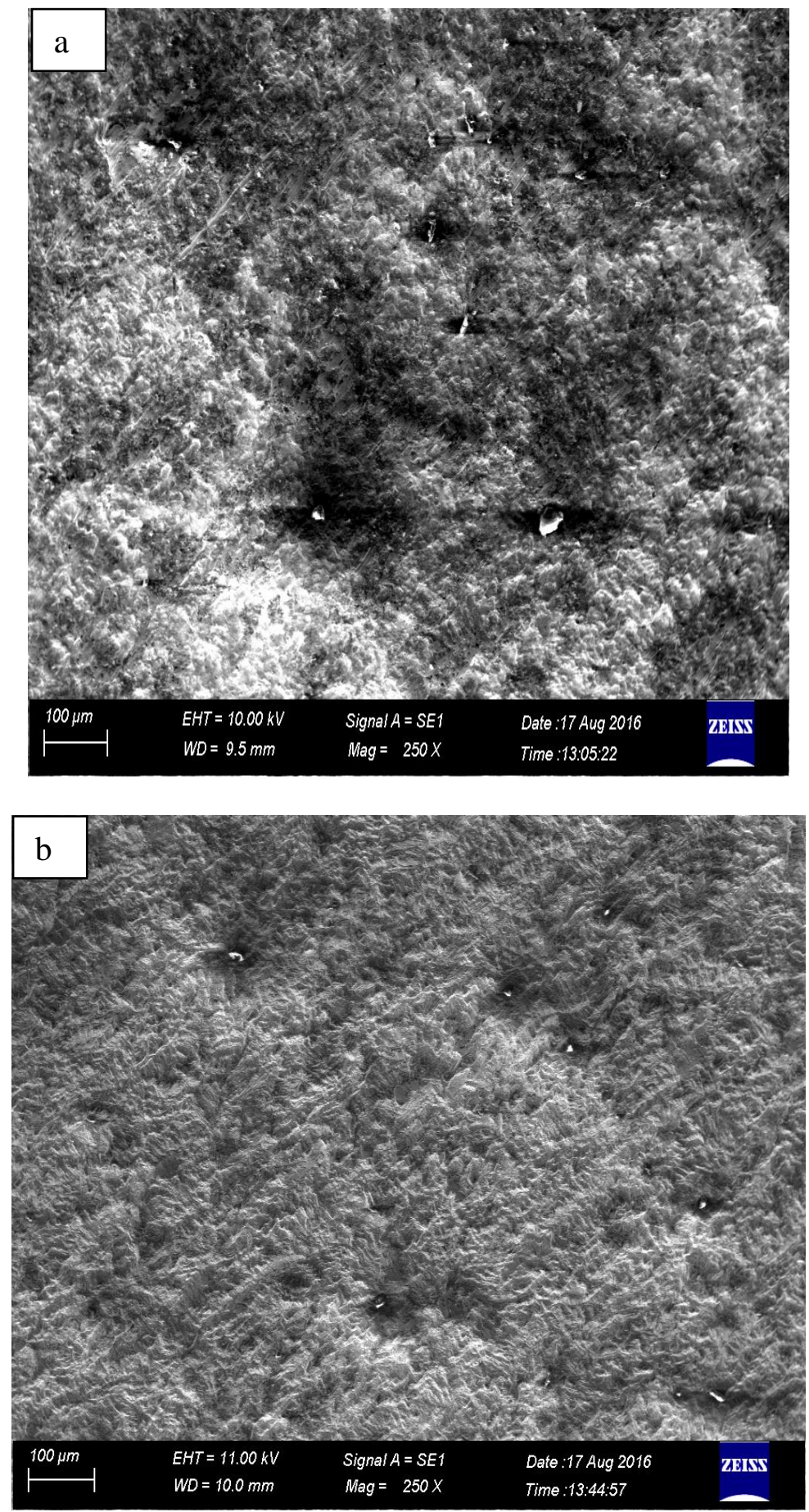

Fig. (14a,b) SEM images of mild steel samples (a) blank (b) with80 ppm 

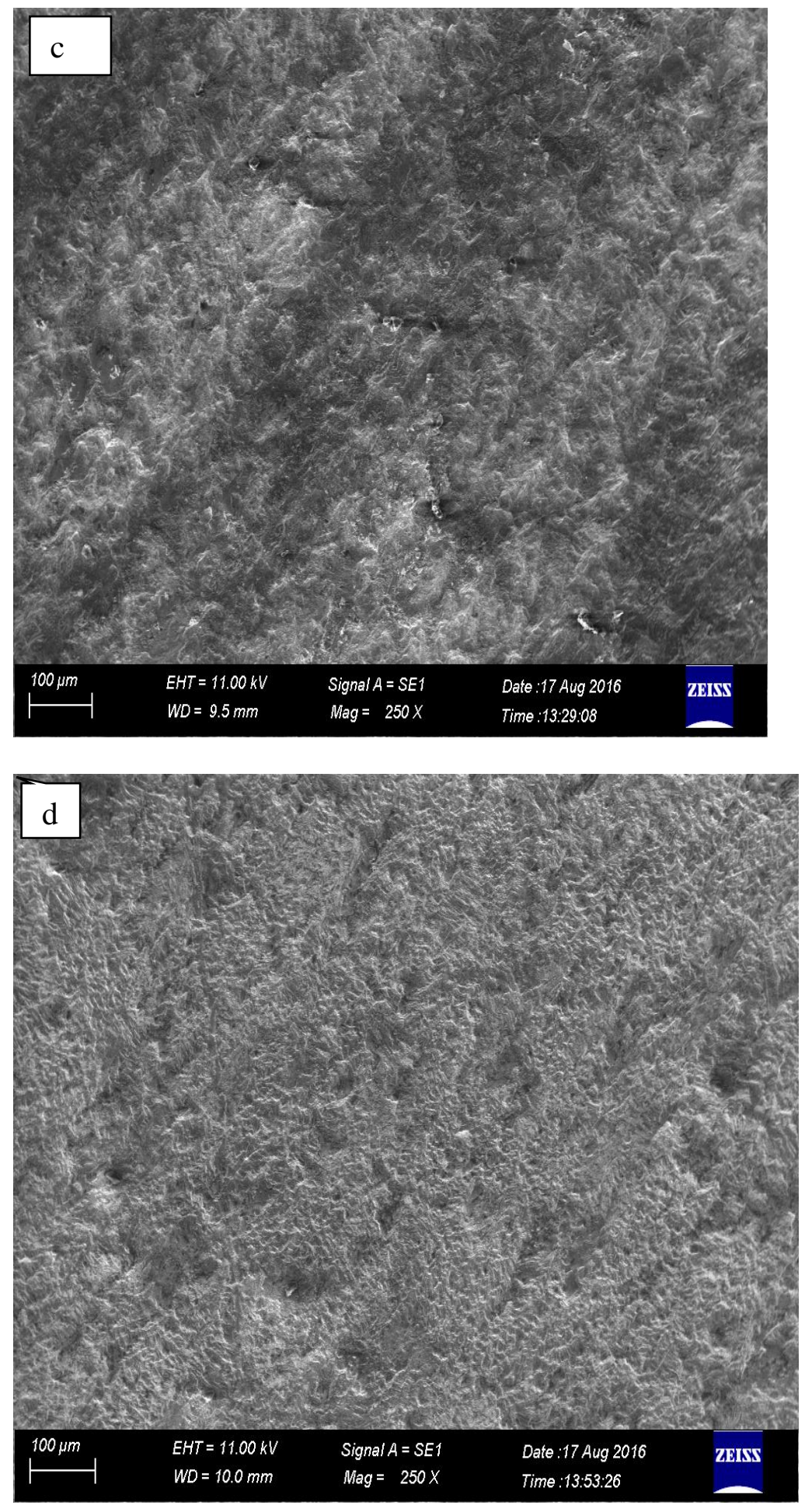

Fig. (15c,d) SEM images of mild steel samples (c) with 240 ppm (d) with 400 ppm 

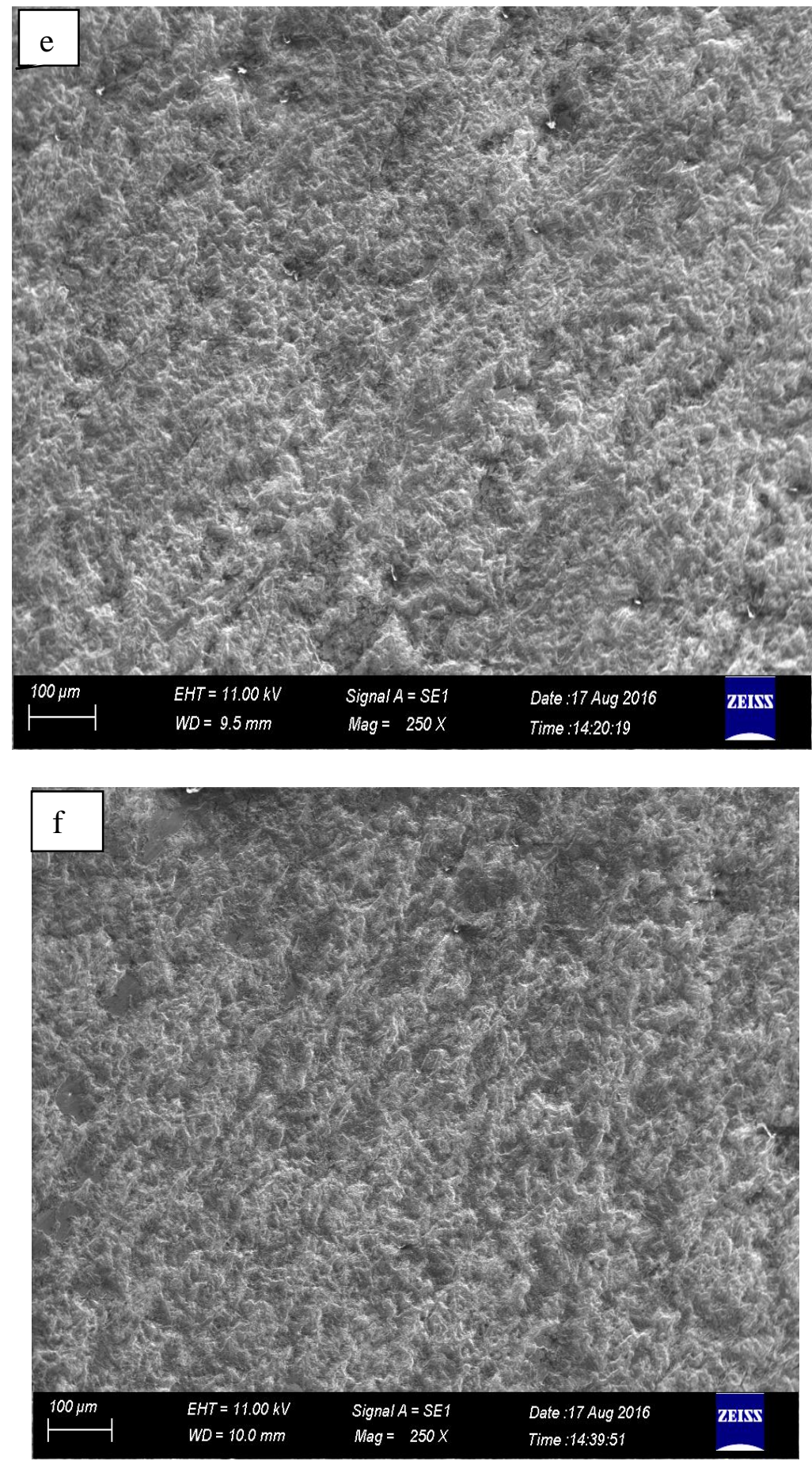

Fig. (16e,f) SEM images of mild steel samples (e) with $800 \mathrm{ppm}$ and (f) with $1200 \mathrm{ppm}$ of LU inhibitor after immersion in 1M H2SO4 for $72 \mathrm{hr}$. 


\section{Conclusions}

i. The Linum Usitatissimum can successfully be used to inhibit the corrosion of mild steel in $1 \mathrm{M} \mathrm{H}_{2} \mathrm{SO}_{4}$.

ii. The results of corrosion inhibition of mild steel in $1 \mathrm{M} \mathrm{H}_{2} \mathrm{SO}_{4}$ solutions using polarization studies, impedance measurements and weight loss measurements are in agreement.

iii. The value of inhibition efficiency increases with increasing inhibitor concentration, but decreases with increasing temperature.

iv. The adsorption of LU on mild steel surface obeys the Langmuir adsorption isotherm.

v. The phenomenon of physisorption is proposed from the activation energy and thermodynamic parameters obtained.

vi. The values of $\Delta G$ ads and $E_{\mathrm{a}}$ indicate that the $\mathrm{LU}$ adsorption process on the metal surface was spontaneous, and that efficiency of corrosion inhibition increases with increasing inhibitor concentration.

vii. SEM and FTIR prove that $\mathrm{LU}$ inhibits mild steel corrosion in $1 \mathrm{M} \mathrm{H}_{2} \mathrm{SO}_{4}$.

\section{References}

[1] Shahid, M., Corrosion protection with eco-friendly inhibitors. Advances in Natural Sciences: Nanoscience and Nanotechnology, 2011. 2(4): p. 043001.

[2] Gobara, M., A. Baraka, and B. Zaghloul, Inhibition of mild steel corrosion in sulfuric acid solution using collagen. Research on Chemical Intermediates, 2015. 41(10): p. 7245-7261.

[3] Hegazy, M., et al., An investigation of three novel nonionic surfactants as corrosion inhibitor for carbon steel in 0.5 MH 2 SO 4. Corrosion Science, 2012. 54: p. 219230.

[4] Kamal, C. and M. Sethuraman, Hydroclathrus clathratus marine alga as a green inhibitor of acid corrosion of mild steel. Research on Chemical Intermediates, 2013. 39(8): p. 3813-3828.

[5] Ghareba, S. and S. Omanovic, Interaction of 12-aminododecanoic acid with a carbon steel surface: towards the development of 'green'corrosion inhibitors. Corrosion Science, 2010. 52(6): p. 2104-2113.

[6] Palomar-Pardavé, M., et al., Influence of the alkyl chain length of 2 amino 5 alkyl 1, 3, 4 thiadiazole compounds on the corrosion inhibition of steel immersed in sulfuric acid solutions. Corrosion Science, 2012. 54: p. 231-243.

[7] Umoren, S.A., Y. Li, and F.H. Wang, Effect of polyacrylic acid on the corrosion behaviour of aluminium in sulphuric acid solution. Journal of Solid State Electrochemistry, 2010. 14(12): p. 2293-2305.

[8] Tait, W.S., An introduction to electrochemical corrosion testing for practicing engineers and scientists. 1994: PairODocs Publications.

[9] Deng, S. and X. Li, Inhibition by Ginkgo leaves extract of the corrosion of steel in $\mathrm{HCl}$ and $\mathrm{H} 2 \mathrm{SO} 4$ solutions. Corrosion Science, 2012. 55: p. 407-415.

[10] Langmuir, I., The adsorption of gases on plane surfaces of glass, mica and platinum. Journal of the American Chemical society, 1918. 40(9): p. 1361-1403.

[11] El-Awady, A., B. Abd-El-Nabey, and S. Aziz, Kinetic-thermodynamic and adsorption isotherms analyses for the inhibition of the acid corrosion of steel by cyclic and open-chain amines. Journal of the Electrochemical Society, 1992. 139(8): p. 2149-2154. 
[12] Singh, A. and M. Quraishi, The extract of Jamun (Syzygium cumini) seed as green corrosion inhibitor for acid media. Research on Chemical Intermediates, 2015. 41(5): p. 2901-2914.

[13] Zadeh, A.R.H., I. Danaee, and M.H. Maddahy, Thermodynamic and adsorption behaviour of medicinal nitramine as a corrosion inhibitor for AISI steel alloy in HCl solution. Journal of Materials Science \& Technology, 2013. 29(9): p. 884-892.

[14] Hegazy, M., et al., Three novel di-quaternary ammonium salts as corrosion inhibitors for API X65 steel pipeline in acidic solution. Part I: experimental results. Corrosion Science, 2014. 81: p. 54-64.

[15] Atkins, P. and J. De Paula, Atkins' physical chemistry. New York, 2006.

[16] Adawy, A.I., M.A. Abbas, and K. Zakaria, New Schiff base cationic surfactants as corrosion inhibitors for carbon steel in acidic medium: weight loss, electrochemical and SEM characterization techniques. Research on Chemical Intermediates, 2016. 42(4): p. 3385-3411.

[17] Baraka, A., P. Hall, and M. Heslop, Preparation and characterization of melamineformaldehyde-DTPA chelating resin and its use as an adsorbent for heavy metals removal from wastewater. Reactive and Functional Polymers, 2007. 67(7): p. 585600.

[18] Morad, M., Inhibition of iron corrosion in acid solutions by Cefatrexyl: Behaviour near and at the corrosion potential. Corrosion Science, 2008. 50(2): p. 436-448.

[19] Kamal, C. and M. Sethuraman, Spirulina platensis-A novel green inhibitor for acid corrosion of mild steel. Arabian Journal of Chemistry, 2012. 5(2): p. 155-161.

[20] Abbasov, V., et al., A study of the corrosion inhibition of mild steel C1018 in CO 2saturated brine using some novel surfactants based on corn oil. Egyptian Journal of Petroleum, 2013. 22(4): p. 451-470.

[21] $\mathrm{Xu}, \mathrm{B}$,, et al., Experimental and theoretical evaluation of two pyridinecarboxaldehyde thiosemicarbazone compounds as corrosion inhibitors for mild steel in hydrochloric acid solution. Corrosion Science, 2014. 78: p. 260-268.

[22] Verma, D.K. and F. Khan, Corrosion inhibition of mild steel in hydrochloric acid using extract of glycine max leaves. Research on Chemical Intermediates, 2016. 42(4): p. 3489-3506.

[23] Ménager, M., C. Azémard, and C. Vieillescazes, Study of Egyptian mummification balms by FT-IR spectroscopy and GC-MS. Microchemical Journal, 2014. 114: p. 32-41.

[24] Bahrami, M., S. Hosseini, and P. Pilvar, Experimental and theoretical investigation of organic compounds as inhibitors for mild steel corrosion in sulfuric acid medium. Corrosion Science, 2010. 52(9): p. 2793-2803.

[25] Abu-Dalo, M., A. Othman, and N. Al-Rawashdeh, Exudate gum from acacia trees as green corrosion inhibitor for mild steel in acidic Media. Int. J. Electrochem. Sci, 2012. 7(10): p. 9303-9324.

[26] $\mathrm{Cao}, \mathrm{H} .$, et al., Infrared spectra analysis of $\mathrm{OH}$ on aggregate structure formation of oleamide in sulfuric acid solution. Separation and Purification Technology, 2015. 145: p. 98-103.

[27] Ji, G., et al., Aqueous extract of Argemone mexicana roots for effective protection of mild steel in an $\mathrm{HCl}$ environment. Research on Chemical Intermediates, 2016. 42(2): p. 439-459. 